\title{
Pb Compatibility in Ion Implanted Zircon
}

\author{
J. Lian, K. Sun, L. M. Wang, R. C. Ewing \\ Dept. of Nuclear Engineering \& Radiological Sciences, University of Michigan, Ann \\ Arbor, MI 48109-2104
}

Zircon ( $I_{1} /$ amd, $\left.Z=4\right), \mathrm{ZrSiO}_{4}$, has been widely used in age dating of crustal events due to its widespread distribution in the continental crust and tendency to concentrate trace elements, particularly lanthanides and actinides. Because of the importance of $\mathrm{U}-\mathrm{Th}-\mathrm{Pb}$ isotopic dating of zircon in interpreting crustal events, it is important to understand the equilibrium and kinetic behavior of both the parent (U, Th) and daughter $(\mathrm{Pb})$ elements in the zircon matrix. Usually, $\mathrm{Pb}$ exhibits incompatible behavior toward zircon because of unmatched ionic size and charge balance, and only $\mathrm{Pb}^{4+}$ is conducive to substitution for $\mathrm{Zr}^{4+}$ in the zircon lattice. Natural zircons concentrate $\mathrm{U}$ and Th during growth and tend to reject $\mathrm{Pb}$, so most $\mathrm{Pb}$ in zircons is produced in situ from decay. However, some non-radiogenic $\mathrm{Pb}(\sim 2 \mathrm{ppb}$ to $80 \mathrm{ppm})$ does exist even in zircons apparently unaffected by contamination or metamictization [1]. It is possible that radiogenic lead atoms assume the same valence as common $\mathrm{Pb}$ incorporated while zircon crystallized in which case the two are indistinguishable. Therefore, the incorporation of $\mathrm{Pb}$ in zircons during its growth and its diffusion later over geologic time, unless properly recognized, pose risk of overestimation or underestimation of ages by the U-Pb technique.

In this study, the microstructure evolution of zircons upon ion damage and the compatibility of $\mathrm{Pb}$ in zircon matrix have been studied by transmission electron microscopy after $300 \mathrm{keV} \mathrm{Pb}^{+}$ion implantation at room temperature. At an ion fluence of $1 \times 10^{16}$ ions $/ \mathrm{cm}^{2}$ (Fig. 1A), a continuous amorphous layer with a thickness of $\sim 155 \mathrm{~nm}$ has been created by $\mathrm{Pb}^{+}$implantation as a result of radiation damage above the critical damage level $(0.4 \sim 0.5 \mathrm{dpa})$ for amorphization. In addition to the amorphous layer, $\mathrm{a} \mathrm{Pb}$ nanoparticle layer with a thickness of $\sim 100 \mathrm{~nm}$ formed in zircon matrix implanted by $1 \times 10^{17}$ ions $/ \mathrm{cm}^{2}$, as observed by high-resolution TEM (Fig. 2A), electron and X-ray diffractions. The $\mathrm{Pb}$ nanocrystal formation in zircon matrix is further evidenced by a high-angle annual dark field scanning TEM (HAADF-STEM) image (Fig. 2B). At a lower ion fluence, no evidence of nanocrystal formation has been found (Fig. 3A), and STEM-EDX scanning along the white line in Fig. 3A indicates a Gaussian distribution of $\mathrm{Pb}^{+}$ions in zircon matrix (Fig. 3B) with a peak concentration of $\sim 3$ atom $\%$ at a depth of $\sim 76 \mathrm{~nm}$, close to the ion range $(\sim 67 \mathrm{~nm})$ and distribution of $300 \mathrm{keV} \mathrm{Pb}$ in amorphous zircon matrix, as calculated by SRIM-2000 code. This result suggests that no significant $\mathrm{Pb}^{+}$ion redistribution occurs a result of subsequent ion implantation due to a slow diffusion in zircon matrix at room temperature. When the ion concentration exceeds $\sim 3.5$ atom $\%$ (at $10^{17}$ ions $/ \mathrm{cm}^{2}$ ), $\mathrm{Pb}$ nanoparticles precipitated at room temperature from the amorphous zircon matrix. This suggests that $3.5 \mathrm{~Pb} \%$ is above the solubility of $\mathrm{Pb}$ in zircon, and this leads to the formation of $\mathrm{Pb}$ nanoparticles [2].

[1] E. B. Watson et al., Chemical Geology 141, (1997) 19.

[2] This work was supported by USDOE under grant DE-FG02-97ER45656. 

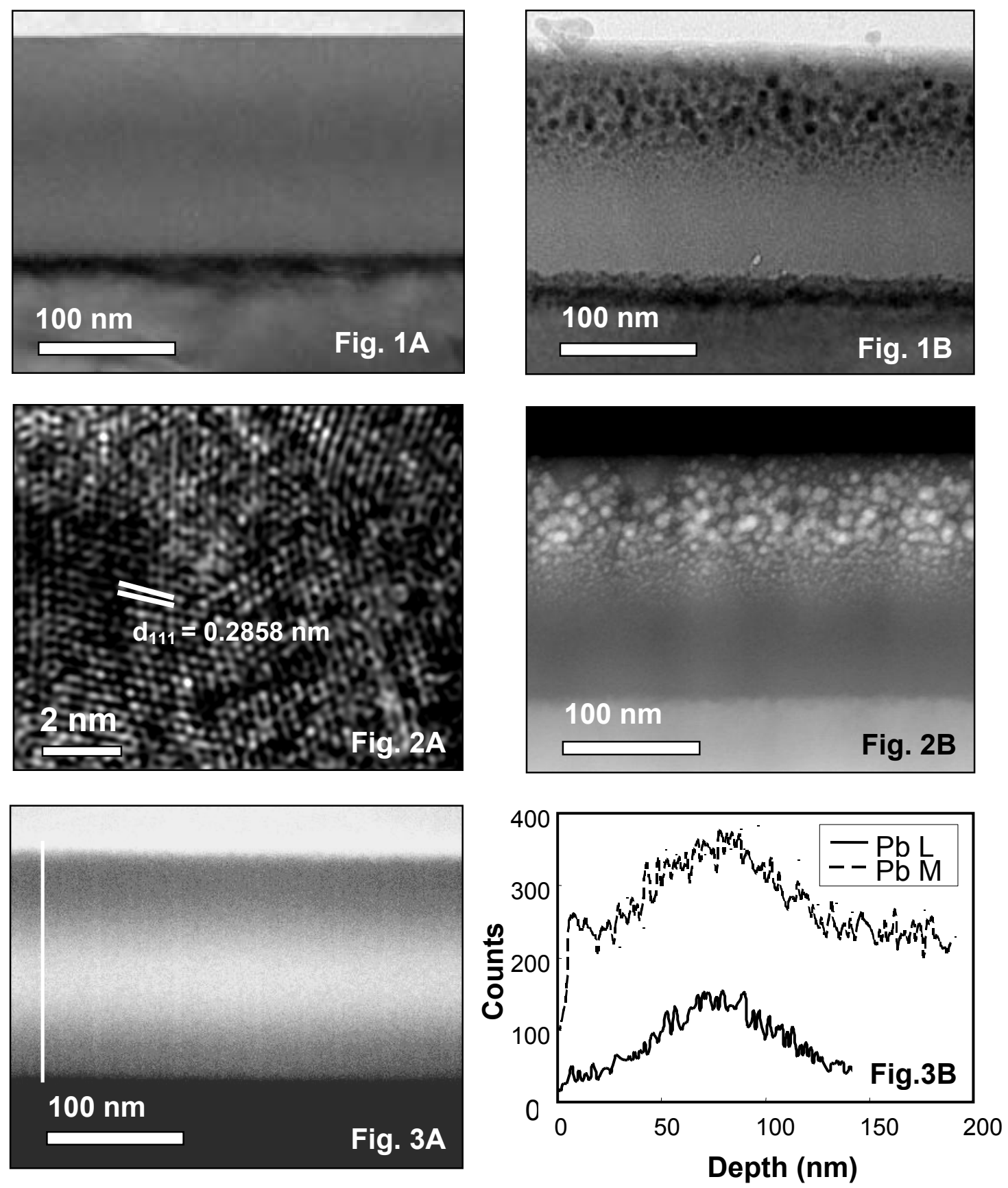

FIG. 1. Cross-sectional TEM images of $300 \mathrm{keV} \mathrm{Pb}^{+}$implanted zircons showing the formation of amorphous layer and nanoparticles at ion fluences: (A) $1 \times 10^{16}$ and (B) $1 \times 10^{17}$ ions $/ \mathrm{cm}^{2}$, respectively.

FIG. 2. High-resolution TEM (A) and HAADF-STEM (B) images showing the formation of $\mathrm{Pb}$ nanoparticles $\left(1 \times 10^{17}\right.$ ions $\left./ \mathrm{cm}^{2}\right)$.

FIG. 3. (A) HAADF-STEM image showing the $\mathrm{Pb}^{+}$elemental distribution in implanted zircon matrix $\left(1 \times 10^{16}\right.$ ions $\left./ \mathrm{cm}^{2}\right)$; $(\mathrm{B}) \mathrm{Pb}^{+}$profile in zircon matrix obtained by STEM-EDS scanning along the white line in Fig. $3 \mathrm{~A}$. 